\title{
Avaliação do uso da casca do fruto e das folhas de Caesalpinia ferrea Martius como suplemento nutricional de Fe, Mn e Zn
}

\author{
Evaluation of the use of the fruit peel and leaves of Caesalpinia ferrea Martius \\ as a nutritional supplement of Fe, $\mathrm{Mn}$ and $\mathrm{Zn}$
}

\author{
Clelivaldo Santos da SILVA ${ }^{1}$, Patrícia de Oliveira NUNES ${ }^{1}$, Cleide Samara Tavares MESCOUTO ${ }^{1}$, \\ Regina Celi Sarkis MÜLLER ${ }^{1}$, Dulcidéia da Conceição PALHETA², Kelly das Graças FERNANDES ${ }^{1 *}$
}

\section{Resumo}

As plantas medicinais podem ser usadas como fontes alternativas de nutrientes minerais na dieta alimentar. Elementos como ferro, manganês e zinco apresentam biodisponibilidade variável em função de suas formas químicas (espécies) presentes em um alimento. Este trabalho tem como objetivo avaliar o teor e a biodisponibilidade de ferro, manganês e zinco em extratos da casca do fruto e das folhas de Caesalpinia ferrea Martius por Espectrometria de Absorção Atômica com Chama (FAAS). Os agentes extratores testados foram as soluções de NaOH 0,05 mol. $\mathrm{L}^{-1}$, tampão Tris-HCl 0,05 mol.L $\mathrm{L}^{-1}(\mathrm{pH}=8)$, tampão Tris- $\mathrm{HCl} 0,05$ mol. $\mathrm{L}^{-1}(\mathrm{pH}=8)$ em dodecil sulfato de sódio (SDS) $1 \%$ (m/v), HCl 0,05 mol. $\mathrm{L}^{-1}$ e água quente $\left(60^{\circ} \mathrm{C}\right)$. A casca do fruto e as folhas de Caesalpinia ferrea Martius apresentaram níveis altos de ferro e manganês quando comparados aos de outras plantas medicinais. Os elementos estudados mostraram predominante associação com compostos de alta e baixa massa molecular, espécies solúveis e insolúveis em água. Dentre os elementos analisados, o ferro apresentou melhor biodisponibilidade na casca do fruto e nas folhas. Manganês e zinco se mostraram mais biodisponível nas folhas. A casca do fruto e as folhas de Caesalpinia ferrea Martius podem ser uma fonte alternativa de ferro, manganês e zinco na dieta alimentar.

Palavras-chave: ferro; manganês; zinco; biodisponibilidade; Caesalpinia ferrea Martius.

\begin{abstract}
Medicinal plants can be used as alternative sources of mineral nutrients in the alimentary diet. Elements such as iron, manganese, and zinc present variable bioavailability due to their chemical form (species) present in foods. This work has the objective of evaluating the concentration and bioavailability of iron, manganese, and zinc in extracts of the peel and leaves of Caesalpinia ferrea Martius by Flame Atomic Absorption Spectrometry (FAAS). The extraction agents tested were 0.05 mol.L-1 NaOH, 0.05 mol.L-1 Tris- $\mathrm{HCl}$ buffer ( $\mathrm{pH} 8.0$ ), 0.05 mol.L ${ }^{-1}$ Tris- $\mathrm{HCl}$ buffer ( $\mathrm{pH} 8.0$ ) containing $1 \%\left(\mathrm{~m} / \mathrm{v}\right.$ ) sodium dodecylsulfate (SDS), $0.05 \mathrm{~mol} . \mathrm{L}^{-1} \mathrm{HCl}$, and hot water at $60^{\circ} \mathrm{C}$. The peel and leaves of Caesalpinia ferrea Martius presented higher levels of iron and manganese when compared to other medicinal plants. The elements studied showed predominant association with compounds of high and low molecular weight and soluble and insoluble species in water. Among the analyzed elements, the iron presented the best bioavailability in the peel and leaves of the fruit. Manganese and zinc presented higher bioavailability in the leaves. The peel and leaves of Caesalpinia ferrea Martius can be an alternative source of iron, manganese, and zinc in the alimentary diet.
\end{abstract}

Keywords: iron; manganese; zinc; bioavailability; Caesalpinia ferrea Martius.

\section{Introdução}

O uso de plantas medicinais é uma prática comum no país, a qual tem sido transmitida de geração em geração e é realizada por meio do extrativismo. A utilização e comercialização de plantas medicinais têm sido estimuladas pela crescente demanda da indústria por novas fontes naturais de medicamentos e, por outro lado, devido aos efeitos colaterais causados pelos fármacos sintéticos que estimulam o aproveitamento de medicamentos de origem vegetal ou, em muitos casos, porque representam a única fonte de medicamentos, especialmente nos lugares mais isolados e distantes, e como resposta aos problemas imediatos de saúde (VEIGA JÚNIOR; PINTO; MACIEL, 2005).
A Organização Mundial da Saúde estima que $80 \%$ da população mundial depende da medicina tradicional para suas necessidades básicas de saúde e que quase $85 \%$ da medicina tradicional envolve o uso de plantas medicinais, seus extratos vegetais e seus princípios ativos (AKERELE, 1993).

Alguns nutrientes minerais presentes em plantas possuem um papel preventivo no combate de doenças, mas é importante ressaltar que níveis elevados desses minerais podem ser perigosos e tóxicos ao organismo. Alguns minerais como Co, Cr, $\mathrm{Cu}, \mathrm{Fe}, \mathrm{Mn}, \mathrm{Mg}, \mathrm{Mo}$, Se e Zn são considerados essenciais à saúde por atuarem em importantes vias metabólicas, participando de

Recebido para publicação em 21/7/2008

Aceito para publicação em 21/6/2009 (003695)

Instituto de Ciências Exatas e Naturais, Faculdade de Química, Universidade Federal do Pará - UFPA, Rua Augusto Corrêa, n. 1, CEP 66075-110, Belém - PA, Brasil,

E-mail: kdgfernandes@ufpa.br

${ }^{2}$ Instituto de Saúde e Produção Animal, Universidade Federal Rural da Amazônia - UFRA, Belém - PA, Brasil

${ }^{*}$ A quem a correspondência deve ser enviada 
atividades associadas à síntese de proteínas, vitaminas e controle do metabolismo de diversas enzimas, que atuam em processos de síntese e degradação, necessárias à vida humana (SEILER; SIGEL, 1988; WELZ; SPERLING, 1999).

A determinação do teor total do nutriente mineral ingerido pelo organismo não possibilita traçar um perfil da eficiência de sua absorção. A necessidade de saber a biodisponibilidade do nutriente mineral, ou seja, a proporção do nutriente mineral que é absorvido e utilizado pelo organismo é de suma importância para a nutrição humana. Técnicas de especiação química, como a extração de nutrientes minerais usando diferentes meios extratores, podem auxiliar na avaliação da biodisponibilidade destes minerais, possibilitando a obtenção de novos dados para prever sua absorção (ANDRADE; BARROS; TAKASE, 2003; ANDRADE; ALVES; TAKASE, 2005).

Nos últimos anos, vem sendo crescente o número de estudos envolvendo não apenas a determinação de nutrientes minerais em plantas medicinais (ABOU-ARAB et al., 1999; AJASA et al., 2004; AMIN et al., 2002; ALMEIDA et al., 2002), mas também estudos complementares que forneçam informações mais completas para identificar as formas químicas (espécies) e a estrutura dos compostos aos quais diferentes nutrientes minerais estão associados, representando hoje um aumento significativo de trabalhos na literatura (SANZ MEDEL, 2005; WEBER; KONIECZYNSKI, 2003; BANTAN; MILACIC; MITROVIC, 1999; SILVA; WILLIAMS, 2001; LIPPARD; BERG, 1994).

Caesalpinia ferrea Martius é uma árvore nativa do Brasil, conhecida popularmente como pau-ferro ou jucá. As partes constituintes desta árvore vêm sendo utilizadas na medicina popular para o tratamento de problemas hepáticos, respiratórios e, em especial, para distúrbios gastrintestinais e como cicatrizante. Experimentos obtidos com animais indicaram atividades analgésica, anti-inflamatória e antiúlcera para extratos dos frutos e caule da planta (BACHI; SERTIÉ, 1991, 1994; CARVALHO et al., 1996).

Este trabalho tem como objetivo avaliar o teor total e a biodisponibilidade através da extração de ferro, manganês e zinco na casca do fruto e nas folhas de Caesalpinia ferrea Martius, usando diferentes meios extratores por Espectrometria de Absorção Atômica com Chama (FAAS).

\section{Material e métodos}

\subsection{Instrumentos e acessórios}

Um espectrômetro de absorção atômica com chama, Varian AA 220 (Mulgrave, Victoria, Austrália), equipado com corretor lâmpada de deutério foi usado para a determinação de ferro, manganês e zinco nos digeridos e nas frações obtidas em diferentes meios extratores da casca do fruto e das folhas de Caesalpinia ferrea Martius. Como fonte de radiação foi usada uma lâmpada de catodo oco multielementar operando a $10 \mathrm{~mA}$ para ferro $(\lambda=248,3 \mathrm{~nm})$, manganês $(\lambda=279,5 \mathrm{~nm})$ e zinco $(\lambda=213,9 \mathrm{~nm})$. A resolução espectral foi $0,2 \mathrm{~nm}$ para ferro e manganês e 1,0 nm para zinco. A mistura de ar/acetileno foi utilizada como gás de purga.
Para a digestão das amostras (casca do fruto e folhas), foi utilizado um bloco digestor Tecnal (Modelo TE-040/25-1, Piracicaba, São Paulo, Brasil).

Um banho de ultrassom (Modelo USC 1400, Unique, São Paulo, Brasil) foi usado na extração de ferro, manganês e zinco.

\subsection{Coleta das amostras}

A casca do fruto e as folhas de Caesalpinia ferrea Martius foram coletadas no município de Abaetetuba no Estado do Pará no mês de setembro de 2007. As amostras foram secas em estufa por cerca de 3 dias em temperatura de $30^{\circ} \mathrm{C}$ e posteriormente pulverizadas em gral de porcelana.

\subsection{Preparo da amostra}

A casca do fruto e as folhas de Caesalpinia ferrea Martius foram submetidas ao procedimento de digestão ácida separadamente. Uma massa de aproximadamente $0,3 \mathrm{~g}$ de amostra pulverizada foi pesada em replicata $(n=3)$ e, em seguida, foi transferida para tubos de digestão e, então, foram adicionados 2,0 $\mathrm{mL} \mathrm{HNO}_{3}$ 14 mol. $\mathrm{L}^{-1}$ e $1,0 \mathrm{~mL} \mathrm{H} \mathrm{O}_{2} 30 \%(\mathrm{~m} / \mathrm{m})$. Os tubos de digestão foram colocados no bloco digestor em uma temperatura de $130{ }^{\circ} \mathrm{C}$ durante 8 horas. Após o procedimento de digestão, foram retirados do bloco digestor e resfriados à temperatura ambiente. Após o resfriamento, os digeridos obtidos foram transferidos para frascos volumétricos e os volumes ajustados para $10 \mathrm{~mL}$ com água desionizada. Os brancos analíticos foram preparados pelo mesmo procedimento sem a adição da amostra. Ferro, manganês e zinco foram determinados nos digeridos por FAAS, usando uma curva analítica preparada a partir de soluções de referência em meio 0,7 mol.L ${ }^{-1} \mathrm{HNO}_{3}$.

\subsection{Extração assistida por ultrassom}

Para extração assistida por ultrassom, foi pesado $0,5 \mathrm{~g}$ de amostra em frascos de polietileno de $15 \mathrm{~mL}$ e, em seguida, foram adicionados $5 \mathrm{~mL}$ de agente extrator. Na extração, foram avaliados cinco meios extratores (KANNAMKUMARATH;

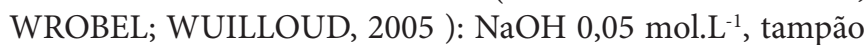
Tris- $\mathrm{HCl} 0,05$ mol.L $\mathrm{L}^{-1}(\mathrm{pH}=8)$, tampão Tris- $\mathrm{HCl} 0,05$ mol.L ${ }^{-1}$ $(\mathrm{pH}=8)$ em SDS $1 \%(\mathrm{~m} / \mathrm{v}), \mathrm{HCl} 0,05 \mathrm{~mol}^{-1} \mathrm{~L}^{-1}$ e água quente $\left(60^{\circ} \mathrm{C}\right)$. As amostras foram sonicadas durante 30 minutos para cada agente extrator. Após a extração, as frações obtidas foram centrifugadas. Os sobrenadantes foram separados do resíduo sólido e, em seguida, submetidos à determinação de ferro, manganês e zinco por FAAS.

\section{Resultados e discussão}

Os teores médios obtidos para ferro, manganês e zinco nos digeridos da casca do fruto e das folhas de Caesalpinia ferrea Martius são apresentados na Figura 1.

Os níveis de ferro e manganês foram maiores nas folhas, quando comparados aos valores obtidos na casca do fruto. Os desvios padrão obtidos foram menores que 3,2\% $(n=3)$. Os teores de ferro encontrados na casca do fruto e nas folhas de Caesalpinia ferrea Martius foram maiores que os valores obtidos 
por (ANDRADE; TEODORO; TAKASE, 2005) para ervas medicinais em pó e secas. Os níveis de ferro, manganês e zinco obtidos em amostras de anador, capim-santo, cidreira, colônia, eparema, hortelã rasteira, malvariço, malva-santa, mastruço e mentrasto estudados por Almeida et al. (2002) foram menores que os valores obtidos destes minerais na casca do fruto e nas folhas de Caesalpinia ferrea Martius.

Os teores médios obtidos para ferro, manganês e zinco nas frações obtidas nos diferentes meios extratores da casca do fruto e das folhas de Caesalpinia ferrea Martius $\left(\mu \mathrm{g} . \mathrm{g}^{-1}\right)$ e os seus respectivos desvios padrão $(\mathrm{n}=3)$ são mostrados na Figura 2.

$\mathrm{Na}$ Figura 2 podemos observar que ferro, manganês e zinco presentes nas diferentes frações obtidas da casca do fruto e das folhas de Caesalpinia ferrea Martius encontram-se no mínimo sob 5 formas químicas.

Os maiores teores de ferro na casca do fruto e nas folhas foram obtidos pelo extrator I. Nas frações obtidas por este extrator, o ferro pode estar associado a compostos de alta e baixa



Figura 1. Teores de Fe, Mn e $\mathrm{Zn}$ na casca do fruto e nas folhas de Caesalpinia ferrea Martins. massa molecular (WUILLOUD; KANNAMKUMARATH; CARUSO, 2004).

Os elementos, manganês e zinco, foram mais bem extraídos na casca do fruto pelo extrator III e nas folhas pelos extratores IV e I, respectivamente. Na casca do fruto, manganês e zinco podem estar associados a espécies insolúveis (KÁLPONA et al., 2007).

Ao contrário do ferro, na casca do fruto, manganês e zinco podem estar associados a espécies solúveis (MOUNICOU; MEIJA; CARUSO, 2004), enquanto nas folhas, manganês pode ser encontrado associado a compostos de baixa massa molecular devido à baixa solubilidade de compostos protonados, como por exemplo, proteínas (WUILLOUD; KANNAMKUMARATH; CARUSO, 2004).

Segundo Vulkan et al. (2002), a forma orgânica do elemento é a forma de melhor aproveitamento de nutrientes minerais pelo organismo, sugerindo uma melhor biodisponibilidade através de mecanismos de absorção.

Considerando que o extrator III age sob as formas insolúveis, que apresentam biodisponibilidade desfavorecida pelo processo de absorção, enquanto o extrator IV age sob os complexos formados pelo elemento e compostos orgânicos, sugerindo uma melhor biodisponibilidade através dos mecanismos de absorção. Acredita-se que, dentre os elementos estudados, o ferro é o mais biodisponível na casca do fruto. Por outro lado, nas folhas, o ferro se torna mais biodisponível seguido do manganês e zinco.

Técnicas de especiação química que identificam os compostos nas frações obtidas nos diferentes meios extratores podem, em futuros estudos, auxiliar na avaliação da biodisponibilidade de ferro, manganês e zinco associados a esses compostos obtidos neste trabalho e, consequentemente, nos processos de absorção.

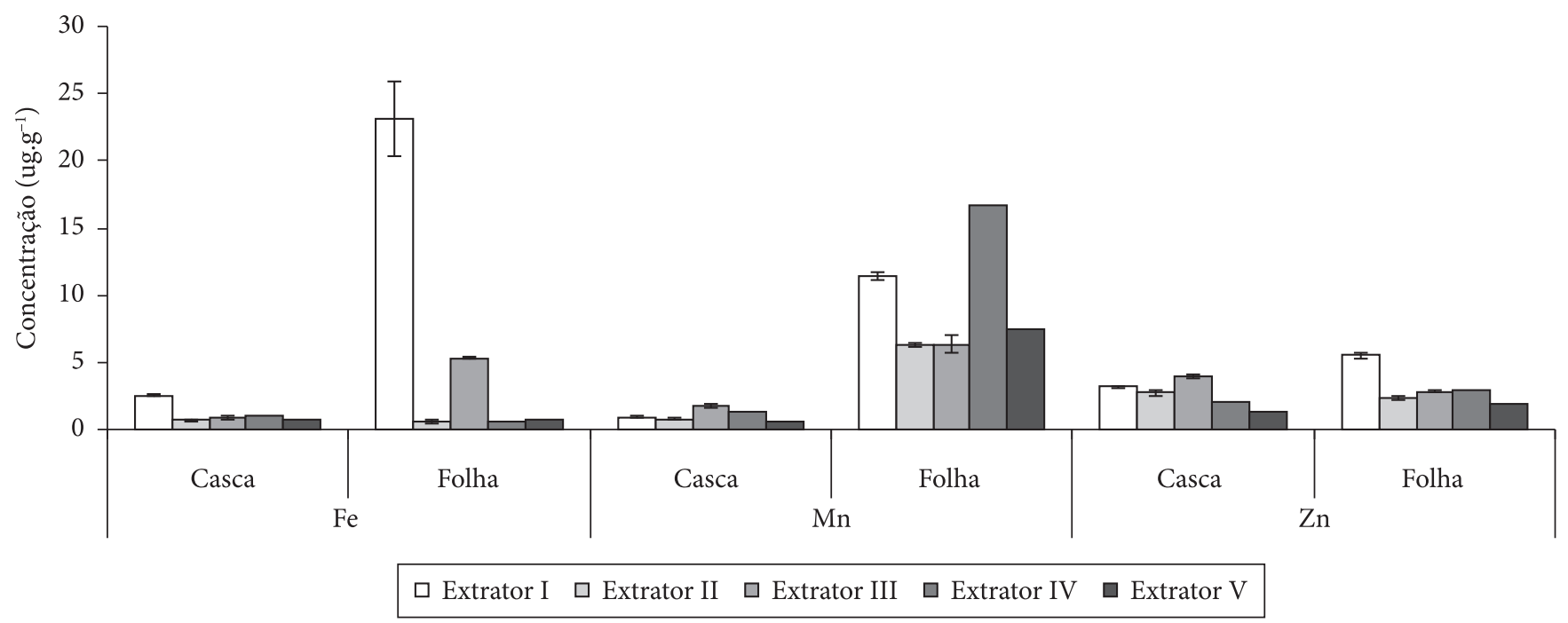

Figura 2. Extração de ferro, manganês e zinco $\left(\mu \mathrm{g} \cdot \mathrm{g}^{-1}\right)$ da casca do fruto e das folhas de Caesalpinia ferrea Martius em diferentes meios extratores $(\mathrm{n}=3)$. Extrator I) NaOH 0,05 mol.. $\mathrm{L}^{-1}$; Extrator II) Tampão Tris-HCl 0,05 mol.L $\mathrm{L}^{-1}$; Extrator III) Tampão Tris-HCl 0,05 mol.L-1 em SDS $1 \%$ (v/v); Extrator IV) $\mathrm{HCl} 0,05$ mol.L ${ }^{-1}$; Extrator V) $\mathrm{H}_{2} \mathrm{O} 60^{\circ} \mathrm{C}$. 


\section{Conclusões}

A casca do fruto e as folhas de Caesalpinia ferrea Martius apresentaram níveis altos de ferro, manganês e zinco quando comparados aos de outras plantas medicinais usadas pela população no tratamento de doenças. Os elementos estudados se encontram sob a forma de, no mínimo, 6 espécies químicas distintas, a extraída em cada um dos meios extratores I, II, III, IV e V e a fração não extraída. Dentre os elementos analisados, o ferro apresentou melhor biodisponibilidade na casca do fruto e nas folhas. Manganês e zinco se mostraram mais biodisponíveis nas folhas. A casca do fruto e as folhas de Caesalpinia ferrea Martius podem ser uma fonte alternativa complementar de ferro, manganês e zinco na dieta alimentar.

\section{Agradecimentos}

Os autores agradecem ao Conselho Nacional de Desenvolvimento Científico e Tecnológico.

\section{Referências bibliográficas}

ABOU-ARAB, A. A. K. et al. Quantity estimation of some contaminants in commonly used medicinal plants in the Egyptian market. Food Chemistry, v. 67, n. 4, p. 357-363, 1999.

AJASA, A. M. O. et al. Heavy trace metals and macronutrients status in herbal plants of Nigeria. Food Chemistry, v. 85, n. 1, p. 67-71, 2004.

AKERELE, O. Summary of who guidelines for the assessment of herbal medicines. HerbalGram, v. 28, p. 13-20, 1993.

ALMEIDA, M. M. B. et al. Determinação de nutrientes minerais em plantas medicinais. Ciência e Tecnologia de Alimentos, v. 22, n. 1, p. 94-97, 2002.

AMIN, M. N. et al. Determination of manganese in herbal medicine samples by slurry-sampling electrothermal atomic absorption spectrometry with a metal tube atomizer. Analytical and Bioanalytical Chemistry, v. 373, n. 3, p. 205-208, 2002.

ANDRADE, E. C. B.; ALVES, S. P.; TAKASE, I. Avaliação do uso de ervas medicinais como suplemento nutricional de ferro, cobre e zinco. Ciência e Tecnologia de Alimentos, v. 25, n. 3, p. 591-596, 2005.

ANDRADE, E. C. B.; BARROS, A. M.; TAKASE, I. Evaluation of the solubility of copper and zinc in a salty, watrry vegetatable soup. Ciência e Tecnologia de Alimentos, v. 23, n. 3, p. 386-388, 2003.

ANDRADE, E. C. B.; TEODORO, A. J.; TAKASE, I. Determinação dos teores de zinco em diferentes extratos de hortaliças do tipo A e B. Ciência e Tecnologia de Alimentos, v. 25, n. 2, p. 265-270, 2005.

BACHI, E.; SERTIÉ, J. A. Antiulcer action of Styrax camporum and Caesalpinia ferrea Martius in rats. Planta Medica, v. 60, n. 2, p. 118-120, 1994.
BACHI, E.; SERTIÉ, J. A. Identificação cromatográfica e ação farmacológica de extratos de Styrax camporum Pohl e Caesalpinia ferrea Martius. Revista Farmácia e Bioquímica da Universidade de São Paulo, v. 27, n. 2, p. 137-149, 1991.

BANTAN, T.; MILACIC, R.; MITROVIC, B. Combination of various analytical techniques for speciation of low molecular weight aluminium complexes in plant sap. Fresenius of Journal Analytical Chemistry, v. 365, n. 6, p. 545-552, 1999.

CARVALHO, J. C. et al. Preliminary studies of analgesic and antiinflammatory properties of Caesalpinia ferrea crude extract. Journal of Ethnopharmacology, v. 53, n. 3, p. 175-178, 1996.

KÁLPONA, E. et al. Selenium speciation studies in Se-enriched chives (Allium schoenoprasum) by HPLC-ICP-MS. Food Chemistry, v. 101, p. 1398-1406, 2007.

KANNAMKUMARATH, S. S.; WROBEL, K.; WUILLOUD, R. G. Studing the distribution pattern of selenium in nut proteins with information obtained from SEC-UV-ICP-MS and CE-ICP-MS. Talanta, v. 66, p. 153-159, 2005.

LIPPARD, S. J.; BERG, J. M. Principles of bioinorganic chemistry. Mill Valley, CA: University Science Books, 1994.

MOUNICOU, S.; MEIJA, J.; CARUSO, J. A. Preliminary studies on selenium-containing proteins in Brassica juncea by size exclusion chromatography and fast protein liquid chromatography coupled to ICP-MS. Analyst, v. 129, n. 2, p. 116-123, 2004.

SANZ MEDEL, A. From metalloproteomics to heteroatom-tagged proteomics. Analytical and Bioanalytical Chemistry, v. 381, n. 1, p. 1-2, 2005.

SEILER, H. G.; SIGEL, H. Handbook on toxicity of inorganic compounds. New York: Marcel Dekker, 1988.

SILVA, J. J. R. F.; WILLIAMS, R. J. P. The biological chemistry of the elements-the inorganic chemistry of life. 2. ed. New York: Oxford University Press Inc., 2001.

VEIGA JÚNIOR, V. F.; PINTO, A. C.; MACIEL, M. A. M. Plantas medicinais: cura segura? Química Nova, v. 28, n. 3, p. 519-528, 2005.

VULKAN, R. et al. Copper and zinc speciation in the solution of a soil-sludge mixture. Journal of Environmental Quality, v. 31, n. 1, p. 193-203, 2002.

WEBER, G.; KONIECZYNSKI, P. Speciation of Mg, Mn and Zn in extracts of medicinal plants. Analytical and Bioanalytical Chemistry, v. 375, n. 8, p. 1067- 1073, 2003.

WELZ, B.; SPERLING, M. Atomic absorption spectrometry. 3. ed. Weinheim: Wiley-VCH, 1999.

WUILLOUD, R. G.; KANNAMKUMARATH, S. S.; CARUSO, J. A. Speciation of nickel, copper, zinc, and manganese in different edible nuts: a comparative study of molecular size distribution by SEC-UV-ICP-MS. Analytical and bioanalytical chemistry, v. 379, n. 3, p. 495-503, 2004. 